DOI 10.5216/ia.v45i3.65092

\title{
COMO É SER DOCENTE NO CENÁRIO EDUCACIONAL EM 2019? A NARRATIVA COMO INSTRUMENTO DO TRABALHO DOCENTE
}

\author{
IVANa Almeida Serpa \\ Universidade Estadual do Rio Grande do Sul (UERGS), Alegrete, Rio Grande do Sul, Brasil \\ FANI AVERBUH Tesseler \\ Universidade Federal do Rio Grande do Sul (UFRGS), Porto Alegre, Rio Grande do Sul, \\ Brasil
}

\begin{abstract}
REsumo: Este artigo objetiva compreender narrativas produzidas por duas docentes sobre sua profissão em Alegrete/Rio Grande do Sul (RS). O estudo, caracterizado como de abordagem qualitativa, utiliza a narrativa enquanto ferramenta de pesquisa em Educação. As narrativas estão baseadas no resgate de vivências e experiências das colaboradoras do estudo, como estratégia de valorização do trabalho docente a partir do reconhecimento das memórias. Em nossas considerações concluintes e re-iniciantes evidenciamos que as narrativas não se limitam à crítica do trabalho desenvolvido pelas entrevistadas. Ao contrário, pressupõem um olhar de compreensão perante a caminhada de cada sujeito no campo educacional, com o intuito de conhecer a realidade docente a partir do ponto de vista de quem se encontra lá.
\end{abstract}

Palavras-chave: Educação. Formação Docente. Vida Profissional. Narrativa.

\section{INTRODUÇÃO}

Discutir o momento atual de desvalorização profissional docente, diante de um estatuto social e econômico fragilizado, requer atentarmos para a formação de professores e suas próprias narrativas sobre a prática, a fim de evidenciar as transformações que acontecem na profissão docente. Nesse sentido, o objetivo geral do estudo é compreender as narrativas produzidas por duas docentes sobre sua profissão em Alegrete/Rio Grande do Sul (RS), cidade situada no extremo oeste do estado, no bioma Pampa.

Ao observar professores da Educação Infantil, Anos Finais do Ensino Fundamental e Médio em seu fazer cotidiano, por vezes parece que, simplesmente, reproduzem os saberes que aprendem na universidade, no âmbito das licenciaturas e nos livros didáticos distribuídos nas escolas, como se fossem os únicos conhecimentos válidos para fundamentar teoricamente as suas práticas pedagógicas nos ambientes escolares.

A proposta aqui desenvolvida parte da necessidade de valorização dos saberes pedagógicos e das experiências que os docentes constroem ao longo de sua carreira 
profissional através da escuta de seus relatos e narrativas para a construção de conhecimentos próprios da profissão. Partimos da premissa de que os docentes, imersos na realidade educativa, constituem um processo constante de reflexão teórico-prática e aperfeiçoamento. Assim, argumentamos a favor da valorização de seu trabalho, que demanda responsabilidades, dedicação e estudo constantes.

Acreditamos que essas articulações fortalecem a formação docente, no sentido de aproximar conhecimentos teóricos e práticos, enquanto possibilitam a produção de saberes que contemplem a realidade escolar e sejam significativos para os professores. Vale salientar que participamos do Programa Institucional de Bolsa de Iniciação à Docência - PIBID, nos anos de 2017 e 2018 e, embora não seja o foco deste trabalho, reforçamos que a proposta do mesmo elenca como objetivo "elevar a qualidade da formação inicial de professores nos cursos de licenciatura, promovendo a integração entre Educação Superior e Educação Básica" (BRASIL, 2010). Esta experiência nos fez repensar a realidade docente.

Além da participação nesse relevante programa de formação inicial de professores e professoras, outra atuação importante foi na iniciação científica vinculada à Universidade Estadual do Rio Grande do Sul- UERGS, instituição de ensino superior pública local. Em razão do desenvolvimento de uma postura profissional investigativa diante das principais discussões que envolvem o cenário educacional, se pode observar que é fundamental o papel da formação para instigar os docentes a desenvolver uma postura pesquisadora.

Considerando as atuais exigências da educação brasileira, pode-se dizer que não é suficiente que os processos formativos de ensino aconteçam nas universidades, escolas e demais instituições educacionais. Esses precisam partir do olhar e da escuta dos docentes e demais profissionais da educação que atuam nas diversas etapas da Educação Básica, garantindo o compartilhamento de saberes por meio da parceria entre escola e universidade (ARROYO, 2000). Em outras palavras, a garantia da qualidade na formação inicial dos professores requer que o diálogo seja destacado como ferramenta de produção de conhecimento.

Em consonância com as perspectivas e concepções que se constituem como futuro de toda docente, evidencia-se os estudos e análises de Arroyo (2000), Nóvoa (2013, 2014), Esteve (2014) e Pereira (2008, 2010) acerca da docência na contemporaneidade. As pesquisas dos referidos autores problematizam as questões e exigências que permeiam a educação na atualidade, apontando a formação profissional dos professores e das professoras como fator essencial para a qualidade da formação escolar de sujeitos.

Nessa perspectiva, que argumenta a favor do reconhecimento do trabalho dos profissionais da educação, propomos a escuta das experiências de professores que atuam na Educação Básica. A partir do exposto, delineamos a seguinte questão: Como é ser professor (a) na escola contemporânea? Tal problematização define a finalidade do estudo, que trata de refletir sobre o que é ser professor/professora diante das funções atribuídas à escola atual. Ao valorizar as histórias de vida de professoras, foi pertinente considerar suas experiências no próprio terreno de sua atuação profissional. 
SERPA, I. A.; TESSELER, F. A.

As narrativas evidenciaram suas trajetórias, motivações profissionais, argumentos e pontos de vista acerca de relevantes questões contemporâneas enfrentadas por docentes em geral. Com base na metodologia utilizada, propusemos algumas discussões oriundas dos relatos das docentes. Analisamos, também, as questões relacionadas à valorização/desvalorização da profissão, aspecto que acarreta inúmeras consequências no trabalho pedagógico e no status social e econômico do professorado.

\section{ESTUDOS E MÉTODOS}

O presente estudo constitui-se numa abordagem qualitativa, atividade que permite ao proponente estudar a trajetória de vida das pessoas através de suas narrativas e reflexões, pois abrange a realidade contextual dos sujeitos, além de tornar possível a representação de suas perspectivas, aliando teorias e conceitualizações (YIN, 2016). Ao inserir-se na realidade das participantes entrevistadas, o método qualitativo se caracteriza por contemplar uma imensidade de temáticas e relações sociais observadas.

Relativamente ao instrumento de coleta de dados utilizado, adotamos a entrevista não estruturada, método em que os questionamentos abertos se sobressaem em relação às perguntas fechadas. A atenção ao estudo da experiência realizada, como narrativa indicativa da realidade vivenciada, é uma maneira de olhar e pensar sobre a história de cada pessoa, que pode se desenvolver pelo contar de vivências ou por seu vivenciar refletido, pois a narrativa, ao descrever a realidade pensada, vem sempre a se constituir como processo de reflexão-sobre-a-ação. Nessa perspectiva é que interessa analisar como os conteúdos são narrados pelas docentes entrevistadas.

Os pontos analisados podem variar conforme os diferentes contextos, realidades e sujeitos por apresentar assuntos e peculiaridades de vida pertinentes ao objetivo que se quer alcançar. Assim, nesse tipo de atividade de coleta de dados, ressalta-se que a "relação entre o pesquisador e o participante não segue um roteiro rígido. [...] A entrevista qualitativa segue um modo conversacional, e a entrevista em si levará a uma espécie de relacionamento social, com a qualidade da relação individualizada para todo participante" (YIN, 2016, p. 121).

A liberdade proporcionada pela pesquisa qualitativa, evidenciando a entrevista não estruturada como instrumento de coleta de dados, incide sobre a possibilidade de analisar o contexto social do participante, articulando-se com suas vivências mais significativas. A abordagem facilita a troca tanto de experiências que constituem a vida dos sujeitos em foco, como dos pesquisadores, quanto de saberes construídos ao longo de suas trajetórias pessoal e profissional, promovendo espaços de valorização das narrativas que apresentam distintas histórias, concepções, perspectivas e culturas.

Nesse sentido, produzir conhecimento está intrinsecamente ligado às vivências que o sujeito carrega consigo, assim como as memórias dos participantes que interagem nos processos de pesquisa. Maturana (2002, p. 55) argumenta que "a ciência - e a validade das explicações científicas - não se constitui nem se funda na referência a uma realidade independente que se possa controlar, mas na construção de um mundo de ações comensurável com nosso viver". O caráter subjetivo, portanto, permite um diálogo profundo, que se distancia dos aspectos objetivos e racionais. 
Adotando essa perspectiva de pesquisa, que valoriza as histórias de vida, realizamos o presente estudo acerca do cenário contemporâneo dos professores. As narrativas de duas docentes em exercício na Educação Básica foi essencial para conhecer histórias e memórias individuais, afinal, a produção do saber sobre a docência precisa contemplar o trabalho daqueles que atuam no cotidiano das instituições de ensino.

A premissa de que a formação do professor deve partir das especificidades e saberes que compõem seu trabalho é um mecanismo para evitar que a educação aconteça desvinculada dos diferentes contextos sociais e econômicos da sociedade atual. Organizar novas propostas metodológicas e educacionais requer ir além das teorias, extremamente importantes, mas que sozinhas não abarcam a singularidade dos sujeitos nem a forma pela qual cada pessoa se constitui em seus conhecimentos, práticas e ações (PEREIRA, 2010).

\section{CONCEPÇÕES DE DUAS DOCENTES DA REDE PÚBLICA DE ENSINO: COMO É SER DOCENTE NO ATUAL CENÁRIO EDUCACIONAL DE 2019?}

O título desta seção esboça a questão que motivou a realização da investigação "Como é ser professor (a) na escola contemporânea?" Essa problematização é oriunda do componente curricular "Docência, formação, identidade e contemporaneidade", do curso de Licenciatura em Pedagogia da UERGS. A temática discutida incentiva o processo de reflexão e criticidade com relação ao contexto profissional dos docentes, levando em conta sua relevância para o reconhecimento das transformações educacionais e desenvolvimento de atitudes e práticas que estejam adequadas ao cenário profissional.

O componente curricular mencionado corrobora para a promoção de uma formação inicial de qualidade dos acadêmicos do curso de Licenciatura em Pedagogia. São contemplados assuntos contemporâneos que preparam os futuros docentes para atuar na educação de forma consciente e responsável, coadunando com a educação integral e com a multiplicidade de sujeitos que integram as instituições de ensino. É uma formação inicial que pretende ultrapassar os conhecimentos teóricos e metodológicos, indo em direção à produção de subjetividades que demonstram autonomia.

Diante do exposto, foi proposta a participação de professores/professoras, fundamentando-se na narrativa enquanto metodologia de pesquisa em educação. A investigação teve como intuito valorizar as histórias, memórias e narrativas dos docentes, ${ }^{1}$ além de aproximar os saberes de acadêmicos, docentes e alunos na direção da coletividade e troca de conhecimentos.

O critério de escolha da escola pautou-se na seleção da instituição da rede municipal de ensino com maior número de educandos matriculados, a fim de encontrarmos mais possibilidades de estudo. Quanto ao processo de aproximação com as participantes, pensamos considerar duas colaboradoras: uma docente que tivesse uma vasta experiência e uma professora em atuação na Educação Básica. O contato deuse de forma presencial, por meio do diálogo com as profissionais e com a equipe diretiva. 
SERPA, I. A.; TESSELER, F. A.

A proposta foi aceita com receptividade pelas docentes e autorizada mediante a assinatura do Termo de Consentimento Livre e Esclarecido, conforme os procedimentos éticos de pesquisa. Posteriormente, realizamos as entrevistas de forma presencial na escola, a partir do agendamento de horários e datas mais adequadas, para não comprometer o trabalho das profissionais.

A formação da docente A inclui o curso Normal do Magistério, graduação em Licenciatura em Pedagogia, concluída em 2009, e especialização em Gestão Educacional, finalizada no ano de 2017. Ela atua há mais de quinze anos nos Anos Iniciais do Ensino Fundamental e Educação Infantil em uma escola localizada em um bairro de Alegrete, na rede municipal de Educação Básica.

A instituição possui mais de 500 alunos matriculados, distribuídos nas etapas de Educação Infantil, Anos Iniciais e Finais do Ensino Fundamental e Educação de Jovens e Adultos. Contempla os serviços de coordenação pedagógica, orientação, gestão escolar, e oferta o Atendimento Educacional Especializado, em conformidade com as legislações e políticas do sistema educacional. A comunidade escolar é constituída por famílias com boas condições de vida, em sua maioria, mas algumas vivem em situação de vulnerabilidade social. A articulação entre escola e meio familiar é considerada positiva, embora alguns responsáveis se ausentem de suas funções educativas.

A docente $A$ escolheu cursar o Magistério e, posteriormente, a Licenciatura em Pedagogia por seu desejo em atuar junto a uma instituição de tamanha relevância para a formação dos sujeitos. Em suas palavras, afirmou:

\footnotetext{
Sempre admirei o trabalho dos educadores, em especial, a profissão de professor. Desde criança, minhas brincadeiras envolviam a sala de aula, a escola, as atividades pedagógicas e o jeito de ensinar aos outros. Ensinar e auxiliar a aprendizagem dos alunos não é uma tarefa fácil. Mesmo sabendo disso, quis estudar sobre educação e docência para estar preparada para atuar com segurança e competência. Não me arrependo dessa escolha, pelo contrário, foi o melhor caminho que eu poderia ter seguido. (Docente A, entrevista, 19 out. 2019).
}

Sua narrativa aponta que a trajetória profissional foi motivada pela certeza de que é possível transformar vidas através da educação, mesmo com a consciência de que esse processo requer o aperfeiçoamento constante. Esse sentimento de satisfação e valorização diante da importância do trabalho docente permite que ela se realize profissionalmente. A entrevistada é casada há mais de dez anos e é mãe de dois filhos, um menino de 2 anos e outro de 8 anos, que estuda na referida escola.

A docente $A$, no decorrer do diálogo, destacou inúmeras reflexões acerca da profissão, considerando as transformações ocorridas na sociedade devido ao avanço dos meios tecnológicos, massificação da educação, desvalorização docente, dentre outras questões relevantes ressaltadas em suas explanações. Independentemente de um cenário onde a docência se fragiliza, a professora ressaltou seu apreço pela profissão que escolheu, ou, como define Arroyo (2000), pelo 'ofício de mestre'. A professora teceu críticas às colegas que generalizam a insatisfação e a desmotivação, uma vez que, segundo suas narrativas, mantém uma postura profissional ativa e pesquisadora. 
Além disso, a docente A defendeu a formação inicial e continuada de professores como um fator primordial para a melhoria da qualidade da educação brasileira e resgatou memórias das quais construiu essa ideia relevante de formação ao afirmar:

\begin{abstract}
O tema do meu trabalho de conclusão de curso da faculdade de pedagogia foi sobre a formação continuada. Eu entrevistei vários professores com o objetivo de investigar e conhecer melhor as práticas realizadas por eles. Estudei autores como Tardif e Nóvoa para me apropriar desse assunto. (Docente A, entrevista, 19 out. 2019).
\end{abstract}

A partir disso, foi possível perceber o quanto uma formação inicial de qualidade incide no desenvolvimento profissional ao longo de sua carreira como docente, já que a professora destaca esses processos em sua trajetória profissional. Ao ser questionada sobre seus entendimentos com relação à profissão docente, ela declarou com propriedade e firmeza: "Acredito que a atuação docente no cenário atual enfrenta muitos desafios, entre eles a desvalorização profissional e as novas exigências da sociedade contemporânea" (Docente A, entrevista, 19 out. 2019).

Suas memórias, construídas no trabalho como professora, constituíram esse olhar com relação à escola, de que esta enfrenta graves problemas. Certamente, a desvalorização do trabalho dos professores e as funções atribuídas à educação escolar servem para a compreensão de como esses processos interferem nas práticas e nos discursos desses profissionais. No entender de Arroyo (2000, p. 21), "ter um oficio significava orgulho, satisfação pessoal, afirmação e defesa de uma identidade individual e coletiva", todavia, atualmente, a profissão não é reconhecida como deveria.

As mudanças que evidenciaram esses novos caminhos da educação e da profissão são anunciadas por Esteve (2014), que relaciona uma série de fatores que promoveram diversas mudanças educacionais, dentre eles destacam-se como transformações mais significativas o aumento de exigências em relação ao docente, uma vez que houve a inibição das responsabilidades da família na escola e o avanço das tecnologias e mídias sociais, que modificou a lógica tradicional de aprendizagem dos alunos e repercutiu no processo pedagógico voltado ao ensino.

Aliado a esses aspectos, encontra-se o fato da massificação do ensino que contribuiu para que fosse impossível a homogeneização social e econômica dos alunos, já que o ensino é universal e obrigatório atualmente, assegurando adequadas condições de acesso e permanência para todos e todas. Isso faz com que os professores desenvolvam funções amplas e complexas para dar conta do contexto social evidenciado nas escolas, portanto, os profissionais passam a assumir "tarefas educativas básicas para compensar as carências do meio social de origem dos alunos, o que configura uma importante diversificação das funções docentes" (ESTEVE, 2014, p. 102).

Esta desvalorização, temática salientada pela docente $A$, é um assunto abordado por diversos autores na discussão acerca da profissão docente. Dentre eles, Nóvoa (2014, p. 227) corrobora esse cenário ao contextualizar a perda de status profissional dos docentes, uma vez que "mesmo que se reitere a importância de sua 
SERPA, I. A.; TESSELER, F. A.

missão, a tendência é considerar sempre que lhes basta dominar bem a sua matéria de ensino e ter uma certa aptidão para a comunicação [...]". Essas considerações conduzem à desvalorização da profissão ao defender que o trabalho docente não demanda grande preparo.

Esses aspectos têm consequências graves no desenvolvimento do trabalho dos professores, que se sentem desmotivados e desvalorizados pela sociedade em geral, já que o estatuto profissional demonstra uma imagem desgastada frente à crise do trabalho do professor. Com relação a essas questões, evidencia-se a necessidade de construção de outros olhares e propostas educacionais que modifiquem e tentem superar os desafios encarados pela profissão docente, olhar que pode ser considerado a partir da narrativa da docente, que argumentou:

\begin{abstract}
Urge um resgate do real papel do educador, da família, da escola. Penso que já não basta apenas ensinar conteúdos, pois eles estão em qualquer plataforma digital. Tampouco a escola não pode abarcar sozinha a solução para todos os problemas que acometem sua comunidade. (Docente A, entrevista, 19 out. 2019).
\end{abstract}

A professora demonstra ter conhecimento sobre as mudanças sociais que refletem na educação escolar. Ao se referir às plataformas digitais, problematiza as consequências da tecnologia na aprendizagem dos alunos, bem como as amplas funções sociais assumidas pela escola. A educação, tanto no que diz respeito à escolarização formal quanto aos conhecimentos construídos no contexto social e familiar, foi se transformando em um processo cada vez mais visto como da escola. $\mathrm{O}$ desenvolvimento cognitivo e intelectual, saber a ser contemplado nas instituições do século XX, passou a aliar-se aos conhecimentos sociais e afetivos, a fim de considerar outras vivências no planejamento de ações escolares.

Entretanto, a escola precisa de apoio da sociedade para fortalecer a formação das crianças, dos jovens e dos adultos que constituem o espaço escolar. Nesse contexto, o trabalho dos professores precisa buscar fortalecer os vínculos e as relações entre escola e famílias a fim de ampliar a participação ativa e democrática em decisões pedagógicas, administrativas e financeiras, projetos pedagógicos e na qualidade da aprendizagem dos alunos e alunas. O desenvolvimento de programas e projetos elaborados pelos sistemas de ensino voltados para a educação dos estudantes e para a formação de professores precisa estar articulado ao meio social das escolas, assumindo o cotidiano como foco principal.

Com o intuito de esclarecer as principais transformações que permearam as últimas décadas, Tardif e Lessard $(2014$, p. 8) ressaltam alguns problemas e desafios que atravessam a escola contemporânea como "a expansão extraordinária dos conhecimentos e a profusão das novas tecnologias da informação e da comunicação, a transformação das estruturas familiares e comunitárias, a ascendência das referências culturais e morais", dentre outros aspectos. O trabalho dos professores passa a compreender novas exigências e conhecimentos diante desse cenário.

Ao professor passou a ser exigida a apropriação de saberes diferenciados, plurais, voltados a diversas competências e atitudes próprias que possam contemplar aspectos cognitivos, afetivos e sociais dos alunos. Mas será que a escola e, sobretudo, os professores podem garantir a qualidade de aprendizagem de todos os conhecimentos 
atribuídos à função educacional? Relativamente a essa questão, Nóvoa (2013, p. 207) defende que é preciso promover "a construção de um espaço público de educação no qual a escola tem o seu lugar, mas que não é um lugar hegemônico, único, na educação das crianças e jovens".

Garantir o apoio de outros profissionais da educação nas propostas pedagógicas escolares é fundamental a fim de que sejam efetivadas e fortalecidas práticas intersetoriais, envolvendo as áreas da saúde, esporte, cultura, assistência social e lazer, com o intuito de oferecer saberes amplos acerca do mundo. Assim, essas ações, ao serem contextualizadas no cotidiano das instituições de ensino, podem chamar a sociedade para suas responsabilidades ao fortalecer a relação entre escola, comunidade e sistemas de ensino.

No momento final da realização da entrevista, a docente $A$ relatou a necessidade de desenvolver projetos educativos em um viés coletivo, em que sejam compartilhados saberes, práticas e experiências no espaço escolar: "precisamos criar redes de aprendizagem, projetos de vida, acolhida e descobertas" (Docente A, entrevista, 19 out. 2019). Esse discurso mostra que, para a docente, ser professor é abraçar os alunos e suas realidades, assim como assegurar a construção de espaços de descobertas e desafios aos educandos, desconstruindo as práticas tradicionais que já não respondem às atuais exigências.

A docente B, por sua vez, tem formação inicial em Ciências, posteriormente obteve a Habilitação em Matemática para lecionar nos Anos Finais do Ensino Fundamental e Ensino Médio, atuando como professora de área específica curricular. Após a formação inicial, cursou a especialização em Metodologia do Ensino da Matemática. A professora entrevistada atuou 26 anos na rede municipal de ensino e ainda se encontra em exercício na rede estadual, somando 24 anos de trabalho.

A instituição na qual trabalha caracteriza-se como uma Escola Estadual de Ensino Médio, que abrange da Educação Infantil ao Ensino Médio, Educação de Jovens e Adultos, além de cursos técnicos. Atende quase dois mil alunos das proximidades e de outras localidades, constituindo uma comunidade escolar de tamanho significativo, cujas famílias possuem condições socioeconômicas bastante diversas, desde contextos menos favorecidos a situações estáveis de vida. A comunidade escolar participa das atividades e projetos que envolvem as famílias, sendo a cooperação e o diálogo questões extremamente valorizadas pela escola.

Relativo à vida pessoal, a professora afirmou que durante a graduação em Ciências conheceu o atual marido, com quem é casada há mais de trinta anos. O casal teve dois filhos e duas filhas, que, atualmente, encontram-se na fase adulta. A entrevistada é oriunda de uma família de produtores agrícolas, possui quatro irmãos, dentre os quais, três com formação superior na área administrativa e contábil. No princípio da narrativa, ela expressou a história da sua escolarização e da escolha pela carreira:

Até o quinto ano do Ensino Fundamental eu e meus irmãos estudamos no interior de Itaqui, ${ }^{2}$ onde meu pai plantava arroz. Tínhamos uma professora que lecionava na nossa casa, era remunerada para nos ensinar os conteúdos trabalhados nas escolas. 
SERPA, I. A. TESSELER, F. A.

Depois, fomos morar na cidade de Alegrete, na qual concluí o Ensino Médio. Nesse período, ensinava meus irmãos e colegas. Sempre me preocupei se estavam aprendendo, mesmo que não fosse de minha responsabilidade. A educação sempre foi do meu interesse. (Docente B, entrevista, 25 out. 2019).

A docente $B$ foi a única da família que decidiu seguir o campo educacional, especialmente a carreira de professora, em razão da admiração pelo trabalho pedagógico dos docentes. O relato demonstrou a paixão e a satisfação pelo trabalho desenvolvido ao longo do exercício da profissão nas escolas públicas, abertura para responder aos questionamentos, resgatar memórias e vivências e expressar suas concepções.

Ainda acerca do processo de escolha pela profissão, a docente relatou que desde o período escolar:

Gostava de ensinar, de explicar os conteúdos para os colegas, principalmente de Matemática. Dava aulas particulares para os colegas e sempre adorei a área e a partir disso fui me direcionando para cursar a graduação de Ciências e fiz a habilitação em Matemática. (Docente B, entrevista, 25 out. 2019).

O prazer em ensinar foi um fato que marcou sua trajetória de escolarização e repercutiu na troca e compartilhamento de saberes e conhecimentos curriculares por meio da interação com os colegas de classe, pois "educar incorpora as marcas de um ofício e de uma arte, aprendida no diálogo de gerações" (ARROYO, 2000, p. 18). O ato de ensinar é considerado como um processo intrínseco à profissão, sem o qual a aprendizagem ficaria comprometida. Diante disso, essas primeiras experiências explicitadas pela professora representam a constituição de uma maneira singular de ensinar os educandos.

Os saberes que constituem o trabalho do professor são oriundos da formação profissional, dos saberes disciplinares e curriculares e, por fim, dos saberes experienciais (TARDIF, 2017). Este último saber refere-se tanto às experiências práticas vividas no cotidiano com os educandos quanto às vivências dos professores enquanto alunos. "Experiência que lhes possibilita dizer [...] quais professores foram significativos em suas vidas, isto é, contribuíram para sua formação humana" (PIMENTA, 2012, p. 20).

As experiências como aluna a estimularam a escolher a profissão docente, especialmente o ensino de Matemática. Quanto à formação inicial, a docente $B$ relatou ter construído "uma boa base a respeito dos componentes de didática da Matemática e também quanto aos conteúdos específicos, com conexão na realidade escolar" (Docente B, entrevista, 25 out. 2019). Os cursos de licenciatura de áreas específicas, em sua maioria, evidenciam a desarticulação entre os componentes curriculares que tratam das metodologias didático-pedagógicas e aqueles direcionados aos conhecimentos específicos da licenciatura (LIBÂNEO, 2013).

Conforme a professora relatou, sua graduação garantiu a qualidade necessária para atuar em sala de aula compreendendo aspectos teórico-práticos que envolvem a docência da Matemática, entretanto, para fortalecer seus saberes disciplinares, 
relacionados aos conhecimentos produzidos pela comunidade científica, cursou a especialização em Metodologia em Ensino de Matemática. Nesse sentido, defendeu que "a formação continuada é muito importante para estar sempre atualizada e, com relação à tecnologia, penso ser necessária a realização de mais cursos de formação" (Docente B, entrevista, 25 out. 2019).

Ao reconhecer a relevância do preparo constante dos professores, a docente $B$ acentuou uma necessidade de formação que repercute no despreparo perante a utilização das tecnologias no desenvolvimento das práticas pedagógicas. $\mathrm{O}$ advento das inovações tecnológicas que transformou a organização da sociedade foi um fenômeno relativamente recente que influencia intensamente a docência, pois o professor "enfrenta a necessidade de integrar no seu trabalho o potencial informativo destas novas fontes, modificando o seu papel tradicional" (ESTEVE, 2014, p. 101).

Além disso, a docente $B$ ressaltou outras questões e desafios que envolvem o cotidiano da docência nos Anos Finais do Ensino Fundamental e Ensino Médio das escolas nas quais trabalha. Dentre eles, apontou em seu discurso a "falta de apoio por parte das famílias de alguns alunos e alunas, a baixa remuneração e falta de tempo para fazer os planejamentos" (Docente B, entrevista, 25 out. 2019). Em razão da inserção das mulheres no mercado de trabalho e da consequente redução do tempo de convívio e dedicação familiar, à escola foram atribuídas novas funções relacionadas à educação das crianças e jovens, resultando na considerável inibição de responsabilidades por parte da família.

Ademais, a baixa remuneração salarial dos professores é um fator fortemente relacionado à falta de tempo para realizar as atividades e funções que envolvem o trabalho docente, já que para adquirir um ganho mensal suficiente para suprir suas necessidades pessoais básicas, os docentes recorrem a extensas jornadas diárias de trabalho. Os professores das áreas específicas de ensino passam a atuar em inúmeras turmas, o que, indubitavelmente, incide na falta de qualidade dos processos de ensino e aprendizagem dos educandos e no cansaço dos profissionais.

Essa perspectiva é expressa pela docente $B$, que relacionou a falta de tempo para os processos de planejamento e avaliação às condições de trabalho e baixa remuneração salarial da categoria: "como eu atuava 60 horas tinha muitas turmas para lecionar e um número excessivo de alunos para fazer o processo de avaliação. Se os professores fossem bem pagos, não seria preciso trabalhar tanto e teríamos mais tempo para nos atualizar" (Docente B, entrevista, 25 out. 2019). Diversas pesquisas enfocam a formação inicial e continuada de professores como questão essencial para a qualidade da Educação Básica, todavia, as condições de trabalho e a adequada valorização da profissão são aspectos imprescindíveis para a educação pública.

Saviani (2009) corrobora a questão ao argumentar a favor da valorização da profissão, pois

as condições precárias de trabalho não apenas neutralizam a ação dos professores, mesmo que sejam bem formados. Tais condições dificultam também uma boa formação, pois operam como fator de desestímulo à procura pelos cursos de formação docente e à dedicação aos estudos. (SAVIANI, 2009, p. 151). 
SERPA, I. A.; TESSELER, F. A.

Assim, formação e condições de trabalho adequados devem receber investimentos que garantam a qualidade no cotidiano escolar.

Sabe-se que a profissão não se limita, tão somente, a desafios e barreiras do cotidiano escolar que dificultam a qualidade do trabalho pedagógico desenvolvido e a formação integral dos sujeitos, mas se constitui de memórias, vivências, experiências, descobertas, aprendizagens e interações sociais entre os envolvidos no processo educativo que possibilitam a troca e a construção/reconstrução de conhecimentos e saberes curriculares. Mais do que o desenvolvimento de conceitos complexos e abstratos, o trabalho em âmbito escolar promove a formação social e humana dos sujeitos.

Defendemos o pressuposto de que atuar como docente abrange a construção de conhecimentos socialmente reconhecidos como importantes para uma formação escolar de qualidade, bem como a socialização afetiva e compromissada tanto com os educandos quanto com relação aos colegas de profissão. Relativamente às memórias que a estimularam a continuar sua carreira de professora, a docente $B$ afirmou:

Sempre gostei de trabalhar com os alunos, de explicar os conteúdos, de conversar e interagir com as turmas. Procurei manter boas relações com meus colegas de profissão para construir um ambiente mais saudável e um clima tranquilo de trabalho. (Docente B, entrevista, 25 out. 2019).

O processo de ensino é novamente enaltecido pela docente, o que evidencia a relevância dessa questão pedagógica para o seu trabalho no ensino da Matemática. Ela aponta, em seu discurso, o diálogo e a interação social como instrumentos efetivos de ensino rumo ao pleno desenvolvimento dos educandos, uma vez que a aprendizagem das relações lógico-matemáticas se consolida "quando houver, no mesmo espaço de ensino e aprendizagem, uma relação de convivência biunívoca entre professor e alunos: O professor ensina, o aluno aprende e o mundo agradece" (PONTES, 2018, p. 171).

O cenário contemporâneo demonstra uma nova realidade que se manifesta no processo de escolarização, em razão das inúmeras transformações pelas quais a sociedade vem percorrendo nas últimas décadas. A massificação do ensino, a ausência de condições adequadas de trabalho nas instituições escolares, o advento de inovações tecnológicas e a desvalorização profissional repercutem na necessidade de formação inicial e continuada adequadas a este contexto, além de valorização aos profissionais que trabalham cotidianamente na educação de crianças, jovens e adultos.

Diante das análises empreendidas, indagamos a docente $B$ sobre seus entendimentos a respeito da docência na atual conjuntura, afinal, como é ser professor (a) no cenário contemporâneo? Segundo ela, "é amar muito a profissão, pois diante de tantas mudanças, desvalorização profissional e desafios que dificultam o trabalho do professor, é preciso gostar de trabalhar em sala de aula e se sentir bem atuando na instituição escolar" (Docente B, entrevista, 25 out. 2019). O discurso demonstra seu encantamento pela profissão, que, mesmo perante fragilidades, precisa ser valorizada.

A articulação entre o discurso das docentes entrevistadas e importantes pesquisadores da temática em âmbito mundial indica que é preciso repensar a profissão docente conforme a realidade que se manifesta, pois 
não podemos continuar a desprezá-lo e a menorizar as capacidades de desenvolvimento dos professores. O projeto de uma autonomia profissional, exigente e responsável, pode recriar a profissão professor e preparar um novo ciclo na história das escolas e dos seus atores. (NÓVOA, 2014, p. 31).

\section{CONSIDERAÇÕES CONCLUINTES E RE-INICIANTES}

Problematizar o cenário da educação e, sobretudo, a desvalorização do trabalho profissional dos professores perante o descontentamento da sociedade exige analisar a formação de tais profissionais no contexto atual. Levando em conta essa questão, objetivamos compreender as histórias, memórias e narrativas relatadas por duas docentes sobre o trabalho dos professores, pautando na narrativa enquanto estratégia metodológica de pesquisa e de valorização da profissão.

O resgate das memórias e histórias de vida dos professores necessita evidenciar os pontos de vista e as concepções construídas ao longo da trajetória pessoal e profissional dos docentes. Partimos do pressuposto de que a narrativa representa as múltiplas realidades vivenciadas no cotidiano dos sujeitos que assumem forte significação diante da formação profissional, sendo capaz de valorizar as singularidades e subjetividades que constituem seu trabalho e a elas mesmas como docentes.

Nesse sentido, nossa proposta, ao embasar-se na narrativa enquanto abordagem metodológica, não objetiva analisar as questões positivas e negativas da atuação das profissionais, nem criticá-las perante os desafios que envolvem a profissão. Ao contrário, as narrativas proporcionam compreender as experiências e as vivências das colaboradoras do estudo como forma de ouvi-las, reconhecê-las e valorizá-las.

Com o intuito de corresponder ao objetivo geral delineado no presente artigo, que visou compreender as narrativas produzidas por duas docentes residentes em Alegrete/RS, foram mencionadas as ideias de importantes pesquisadores do campo da formação de professores. Os autores citados ao longo do texto corroboram as narrativas das professoras, que demonstraram possuir uma formação profissional consistente, resgatando memórias que enfatizam as transformações sociais que permearam os processos voltados à educação.

Este texto pretende contribuir para o reconhecimento dos professores, no sentido de que se sintam capazes de (re)construir saberes específicos do trabalho docente. Isso demanda que sejam fortalecidas a formação inicial e a formação continuada para consolidar o desenvolvimento profissional contextualizado com as exigências da escola contemporânea. As narrativas contribuíram no sentido de valorizar a autoimagem das professoras acerca do trabalho docente, a partir do entendimento de que todos os saberes interagem na identidade da profissão.

Artigo recebido em: 18/08/2020

Aprovado para publicação em: 18/11/2020 
SERPA, I. A.; TESSELER, F. A.

HOW IS IT TO BE A TEACHER AT THE EDUCATIONAL SCENARIO IN 2019? NARRATIVE AS TEACHING WORK INSTRUMENT

ABSTRACT: This article aims to comprehend the narratives produced by two teachers about their profession in Alegrete city/Rio Grande do Sul (RS). The study characterized as a qualitative approach uses a narrative as a reaserch tool in Education. This is based at a vivencial and experiencial rescue since the study colaboraters, as a teachers work valorization strategy and since their memories recognition. At our conclusive and re- inicializing considerations we evidenciate that the narrative is not limited by the critics on the entrewied teachers work. At the contrary the narrative presuppose a comprehention view concerning each participant at the educational field, as to know the teacher reality from the ones that are there.

KEYWORDS: Education. Teacher Training. Professional Life. Narrative.

¿CÓMO SER PROFESOR EN EL ESCENARIO EDUCATIVO EN 2019? LA NARRATIVA COMO INSTRUMENTO DEL TRABAJO DOCENTE

RESUMEN: Este artículo tiene como objetivo comprender las narrativas producidas por dos profesores sobre su profesión en Alegrete / Rio Grande do Sul (RS). El estudio, caracterizado como un enfoque cualitativo, utiliza la narrativa como herramienta de investigación en Educación. Se basa en el rescate de vivencias y vivencias de los colaboradores del estudio, como estrategia de valoración del trabajo docente a partir del reconocimiento de recuerdos. En nuestras consideraciones finales y reiniciadoras, mostramos que la narrativa no se limita a la crítica del trabajo desarrollado por los entrevistados. Por el contrario, la narrativa presupone una mirada de comprensión antes del caminar de cada sujeto en el campo educativo, para conocer la realidad docente desde el punto de vista de quienes allí se encuentran.

PALABRAS CLAVE: Educación. Formación de Profesores. Vida Profesional. Narrativa.

\section{NOTAS}

1 - O entendimento acerca da narrativa de acontecimentos, fazendo uso das histórias de vida e memórias, implica a construção de verdades que revelam os momentos e movimentos vivenciados, historicamente desvalorizados enquanto saber científico.

2 - Município situado na fronteira oeste do Rio Grande do Sul, cuja população estimada é de quase quarenta mil habitantes. 


\section{REFERÊNCIAS}

ARROYO, M. G. Ofício de Mestre: imagens e auto-imagens. Petrópolis, RJ: Vozes, 2000. $251 \mathrm{p}$.

BRASIL. Decreto $n^{\circ} 7.219$, de 24 de junho de 2010. Dispõe sobre o Programa Institucional de Bolsa de Iniciação à Docência - PIBID e dá outras providências. Brasília, 24 de junho de 2010. Disponível em https://www2.camara.leg.br/legin/fed/decret/2010/decreto-7219-24-junho-2010606872-publicacaooriginal-127693-pe.html. Acesso em: 02 out. 2019.

ESTEVE, J. Mudanças sociais e função docente. In. NÓVOA, A. (org.) et al. Profissão professor. 2 ed. Portugal: Porto Editora, 2014. p. 93-124.

LIBÂNEO, J. C. Licenciatura em Pedagogia: a ausência dos conteúdos específicos do ensino fundamental. In: GATTI, B. A. et al. Por uma política nacional de formação de professores. 1. ed. São Paulo: Editora Unesp, 2013. p. 73-94.

MATURANA, H. R. Emoções e linguagem na educação e na política. $3^{a}$ reimpressão. Belo Horizonte: Editora UFMG, 2002. Disponível em http://projetosntenoite.pbworks.com/w/file/fetch/57862785/Humberto\%20Maturana\% $\underline{20-}$ \%20Emo\%C3\%A7\%C3\%B5es\%20e\%20Linguagem\%20na\%20Educa\%C3\%A7\%C3\%A30 \%20e\%20na\%20P\%E2\%80\%A6.pdf. Acesso em: 7 out. 2019.

NÓVOA, A. Nada substitui um bom professor: propostas para uma revolução no campo da formação de professores. In: GATTI, B. A. et al. Por uma política nacional de formação de professores. $1^{\text {a }}$ ed. São Paulo: Editora Unesp. 2013. p. 199-210.

NÓVOA, A. O passado e o presente dos professores. In: NÓVOA, A. (org.) et al. Profissão professor. 2 ed. Portugal: Porto Editora, 2014. p. 13-34.

PEREIRA, M. V. Sobre histórias de vida e autoformação: um enfoque ético e estético. Im. ABRAHÃO, M. H. M. B. (org.). (AUTO) BIOGRAFIA E FORMAÇÃO HUMANA. Porto Alegre: EDIPUCRS, 2010. p. 123-136.

PEREIRA, M. V. Traços de fundamentalismo pedagógico na formação de professores. Revista Iberoamericana de Educación, Madrid, v. 47, n. 5, p. 1-13, 2008. Disponível em: http://www.josenorberto.com.br/josenorberto/Tra\%C3\%A7os\%20de\%20Fundamentalis mo\%20Pedag\%C3\%B3gico\%20-\%20Marcos\%20Villela.PDF. Acesso em: 7 out. 2019. 
SERPA, I. A.; TESSELER, F. A.

PIMENTA, S. G. Formação de professores: identidade e saberes da docência. In: PIMENTA, S. G. Saberes pedagógicos e atividade docente. 8. ed. São Paulo: Cortez, 2012. p. 1538.

PONTES, E. A. S. A arte de ensinar e aprender matemática na educação básica: um sincronismo ideal entre professor e aluno. Revista Psicologia \& Saberes, Maceió, v. 7, n. 8, p. 163-173, 2018. Disponível em https://pdfs.semanticscholar.org/8fa3/389f6a49e0ebc5132dcad6595f560c55a202.pdf. Acesso em 22 mar. 2020.

SAVIANI, D. Formação de professores: aspectos históricos e teóricos do problema no contexto brasileiro. Revista Brasileira de Educação, Rio de Janeiro, v. 14 n. 40 jan./abr., 2009. Disponível em http://www.scielo.br/scielo.php?pid=S141324782009000100012\&script=sci_arttext. Acesso em: 19 maio 2020.

TARDIF, M.; LESSARD, C. O ofício de professor: história, perspectivas e desafios internacionais. 6a ed. Petrópolis, RJ: Vozes, 2014.

TARDIF, M. Saberes docentes e formação profissional. 17. ed. Petrópolis, RJ: Vozes, 2017.

YIN, R. K. Pesquisa qualitativa: do início ao fim. Tradução: Daniel Bueno. Porto Alegre, RS: Penso, 2016.

Ivana Almeida Serpa: Licenciada em Pedagogia pela Universidade Estadual do Rio Grande do Sul (UERGS ALEGRETE) e pós-graduada na especialização em Gestão Escolar pela Uniasselvi. Atualmente, bolsista do Programa Residência Pedagógica e auxiliar pedagógica em uma Escola Municipal de Alegrete.

Orcid: https://orcid.org/0000-0002-6945-8824

E-mail: ivana.serpa1@gmail.com

Fani Averbuh Tesseler: Graduação em História (1979), mestrado em Educação (1994) e doutorado em Educação pela Universidade Federal do Rio Grande do Sul (2006). Atualmente é professora adjunta da Universidade Estadual do Rio Grande do Sul, unidade Alegrete, tendo trabalhado no MEC/UERGS\PARFOR em São Luis Gonzaga/Ulergs e Pedagogia PARFOR/ Uergs em Porto Alegre.

Orcid: https://orcid.org/0000-0002-1311-781X

E-mail: faniatess@gmail.com

Este periódico utiliza a licença Creative Commons Attribution 3.0, para periódicos de acesso aberto (Open Archives Iniciative - OAI).

Inter-Ação, Goiânia, v.46, n.1, p. 294-308, jan./mar. 2021. Disponível em: <http://dx.doi.org/10.5216/ia.v45i3.65092>. 